\title{
A Study of PEFR, FEV1/FVC and MVV among Wood Factory Workers at JAMNAGAR City
}

\author{
Dr. Kirit Sakariya ${ }^{1}$, Dr. Ashvin Sorani ${ }^{2 *}$ \\ ${ }^{1}$ Associate Professor, ${ }^{2}$ Assistant Professor, Department of Physiology PDU Govt Medical College, Rajkot Gujarat India
}

\begin{tabular}{ll}
\hline DOI: $10.36348 /$ sijap.2019.v02i11.001 & | Received: 02.11.2019| Accepted: 06.11.2019|Published: 13.11 .2019
\end{tabular}

*Corresponding author: Dr. Ashvin Sorani

\section{Abstract}

Back ground: Wood workers are more prone to exposed wood dust on regular basis. They are more prone to develop occupational lung diseases. PFT among such workers describe prognosis of such occupational hazards of wood dust. Aim: Based on such back ground we have conducted PEFR, FEV1/FVC and MVV among wood factory workers and compared with healthy individuals. Methods: Present study was carried out at Shree M P Shah Medical College, Jamnagar. We have used MEDSPIROR to collect PFT data in wood workers. Result: Wood workers have significant low PEFR (4.6 \pm 0.34$)$, FEV1/FVC (87.98 \pm 3.66$)$ and MVV (75.02 \pm 3.6$)$ as compare to healthy individual. Prolonged exposure to wood dust in workers shows declining of PFTs.

Keywords: Wood workers, PFT, PEFR, FEV1/FVC, MVV, restrictive lung disease.

Copyright @ 2019: This is an open-access article distributed under the terms of the Creative Commons Attribution license which permits unrestricted use, distribution, and reproduction in any medium for non-commercial use (NonCommercial, or CC-BY-NC) provided the original author and source are credited.

\section{INTRODUCTION}

Spirometry is commonly used in evaluation of certain restrictive and obstructive lung diseases. Development of industrialization and increased population causes tremendous increase in pollution day by day. It will create hazardous effects on respiratory health of people living in developing countries like India. Factory workers employed in saw mill, fibre board, furniture factories are regularly exposed to wood dusts. Those workers work in wood factories (average duration of working is 8-15hours) have tremendous exposure of wood dust during working hours. They are more prone to develop occupational lung disease or have various health issues regarding decreased lung functions. The prevalence of such lung disease about $15 \%$ to $30 \%$ in various part of India.

The elevated inhalable wood dust exposure, lack of awareness of potential, lack of proper ventilation, hazardous effects of wood dust and lack of proper preventive equipment's during working hours increased potential lung damages among workers[1,2,6].

According to Indian factories act 1948 and state factory rules company consultant are using spirometry for periodic medical surveillance to monitor lung functions and respiratory health of workers. PFT parameters like FEV1/FVC ratio, PEFR and MVV have potentially changed in such workers.

Present study was done in wood factories of Jamnagar city. Sea coast area so naturally humid environment and dust particles stay more in environment which damage more as compare to dry air area. On basis of such background we have conducted study on such parameters for wood workers and compared with healthy individuals not involved in such factories.

\section{MATERIAL AND METHODS:}

Study was done on 25 wood workers and compared their lung functions with apparently healthy nonsmokers 25 individual at M P SHAH MEDICAL COLLEGE, JAMNAGAR. All comparable anthropometric measurements taken in workers and healthy individuals with minimum 2 years of work experiences in wood factories for workers. Exclusion of smoking, chronic diseases and any deformity of spinal cord.

Instrument was used MEDSPIROR to examine PFT. We have taken FEV1/FVC ratio, PEFR and MVV among workers and healthy workers. Statistical comparison was done in graph pad prism software. Institutional review board was not existed at the time of study was undertaken. 


\section{RESULTS}

Table-1: Anthropometric measurements of wood workers

\begin{tabular}{|l|l|l|}
\hline Variables & wood workers & Healthy individuals \\
\hline Age & $33.8 \pm 8.41$ & $34.44 \pm 6.4$ \\
\hline Height & $166 \pm 7.1$ & $169.6 \pm 5.7$ \\
\hline Weight & $58.8 \pm 10$ & $63 \pm 9.9$ \\
\hline Working hours & $8.33 \pm 0.74$ & \\
\hline
\end{tabular}

Table-2: PFT Data of wood workers and Healthy individuals

\begin{tabular}{|l|l|l|l|}
\hline Variables & Wood workers & Healthy Individuals & P values \\
\hline FEV1/FVC & $87.98 \pm 3.66$ & $75.85 \pm 4.4$ & $0.04 *$ \\
\hline PEFR & $4.6 \pm 0.34$ & $7.29 \pm 0.31$ & $0.001 * *$ \\
\hline MVV & $75.02 \pm 3.6$ & $110 \pm 2.4$ & $0.001 * *$ \\
\hline
\end{tabular}

(*suggested significant $\mathrm{p}<0.05 * *$ suggested highly significant $\mathrm{p}<0.001$ )

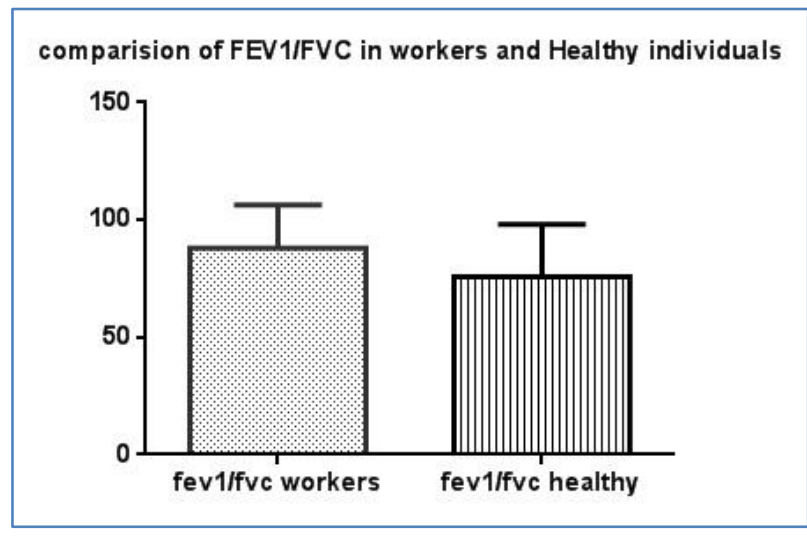

comparision of PEFR in workers and Healthy individuals

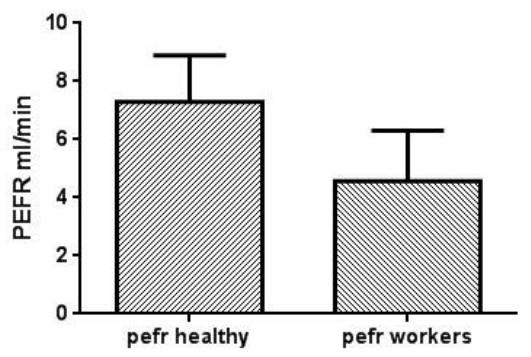

comparision of MVV in workers and Healthy individuals

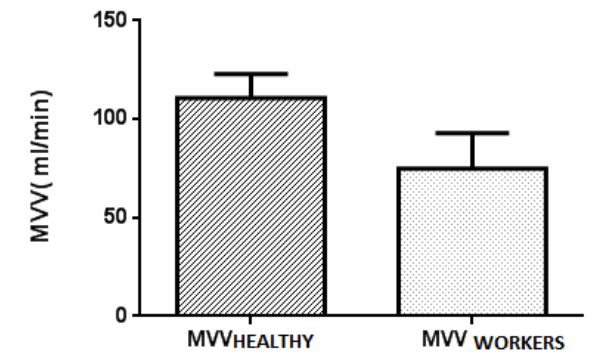

\section{DISCUSSION AND CONCLUSION}

The present study has been carried out in 25 wood workers most of them are suffering from URTI. Erdicosman et al. found same issues of workers with their study. Symptoms of URTI and dry eyes were found in our workers, working more than 10 years [3].
Kamat SR found significantly lower PEFR values in their study as compare to healthy individuals in their study which is comparable PEFR (4.6 \pm 0.34$)$ in our study [4]

Milanowski, J gora et al. found significant lower FEV1/FVC ratio in their study in wood workers which also comparable with our study showing significant lower FEV1/FVC (87.98 33.66) ratio [5].

Pranav s studied MVV significantly lower among wood workers same interpretation was carried by our study with significant lower MVV $(75.02 \pm 3.6)$ as compare to healthy individuals (110 \pm 2.4$)$ [7]

In present study of PFT in wood workers suggest working in wood factories have greater risk of decreased lung functions and more chance develop restrictive lung disease (high FEV1/FVC). Proper protection and ventilation advised to such workers and regular health check up with spirometry also advisable in such workers.

\section{ACKNOWLEDGEMENT}

This study was supported by physiology department of shree MP shah medical college. jamnagar. We are thankful to forest department of jamnagar for granting us permission to conduct study.

\section{REFERENCES}

1. Abrak, P., Belgin, C. (2004). Respiratory symptoms and PFT among furnituredecorators. Ann agrie Environ Med,11,13-17

2. Bussi, M., Gervasio, C. F., Riontino, E., Valente, G., Ferrari, L., Pira, E., \& Cortesina, G. (2002). Study of ethmoidal mucosa in a population at occupational high risk of sinonasal adenocarcinoma. Acta oto-laryngologica, 122(2), 197-201.

3. Osman, E., \& Pala, K. (2009). Occupational exposure to wood dust and health effects on the respiratory system in a minor industrial estate in Bursa/Turkey. International journal of 
occupational medicine and environmental health, 22(1), 43-50.

4. Kamat, S. R., Kamat, G. R., Salpekar, V. Y., \& Lobo, E. (1981). Distinguishing byssinosis from chronic obstructive pulmonary disease: Results of a prospective five-year study of cotton mill workers in India. American Review of Respiratory Disease, 124(1), 31-40.

5. Milanowski, J., Góra, A., Skórska, C., KrysinskaTraczyk, E., Mackiewicz, B., Sitkowska, J., ... \& Dutkiewicz, J. (2002). Work-related symptoms among furniture factory workers in Lublin region (eastern Poland). Annals of Agricultural and Environmental Medicine, 9(1), 99-103.

6. Morales, C. A., Megía, R. L., Del, A. V. Z., Acinas, O., \& Rama, J. (1997). Nasal sinus adenocarcinoma in patients exposed to wood dust in the Community of Cantabria, Spain. Acta otorrinolaringologica espanola, 48(8), 620-624.

7. Pranav, Y. (2006). Shukla:Spirometric evaluation of pulmonary functions in carpenters, Thesis. 